\title{
The status and characteristics of organochlorine pesticide residues in surface water body from the drinking water sources Jinxiuchuan reservoir of China
}

\author{
Youmin Sun ${ }^{\star, 1, a}$, Haibo Lv ${ }^{1, b}, \mathrm{Na} \mathrm{Yu}^{1, \mathrm{c}}$, Xianjie Lin ${ }^{2, \mathrm{~d}}$, Guiqin Zhang ${ }^{1, \mathrm{e}}$ \\ ${ }^{1}$ School of Municipal and Environmental Engineering, Shandong Jianzhu University, Jinan 250101, \\ P. R. China \\ ${ }^{2}$ Depatment of Chemistry, Heze University, Heze 274000, P. R. China

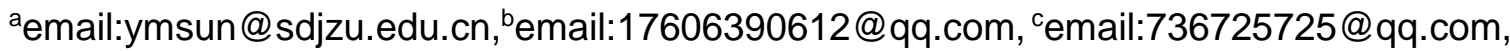 \\ demail:linxianjie@163.com, ${ }^{d} z$ hangguiqin320@163.com
}

Key words: organochlorine pesticides (OCPs); pollution; water body; Jinxiuchuan reservoir Abstracts: The distribution and composition of the 17 organochlorine pesticides (OCPs) in selected samples were investigated with the gas chromatography coupled with Agilent triple quadrupole mass spectrometer (GC-MS). Only DDT has the highest detection rate of $100 \%$ within one year period. The total residual concentrations of 17 OCPs ranged from 0.1794 to $4.6479 \mathrm{ng} / \mathrm{L}$, with a mean concentration of $2.7516 \mathrm{ng} / \mathrm{L}$ and1.3627 $\mathrm{ng} / \mathrm{L}$ in dry and wet seasons, respectively. The highest concentration of the detected pesticides was far below the maximum allowable limits of drinking water sources standards of China and the threshold value of the US EPA. According to the indicators of the ratio values of (DDD+DDE)/DDT and $\alpha-\mathrm{HCH} / \gamma-\mathrm{HCH}$, composition analyses and the source of pollution were also discussed in this study. It indicated that the origin of OCPs were historical residues and a recent usage or discharge of HCHs and DDTs into the Jinxiuchuan reservoir. In general, the concentrations of OCPs in the surface water body of Jinxiuchuan reservoir were much lower than others drinking water sources, and the risk was very low. Nevertheless, additional work including the monitoring investigation should be strengthened to guarantee the safety of drinking water.

\section{Introduction}

Organochlorine pesticides (OCPs), one of the persistent organic pollutants (POPs) groups, are ubiquitous in the environmental matrixes ${ }^{[1]}$, which attracted wide attention because of their persistence, long-range transportable nature, as well as endocrine disrupting effects. According to the research and survey, OCPs were often detected in waters, sediments and mussels from the marine environment of the most cities ${ }^{[2]}$. Jinxiuchuan reservoir, one of surface drinking water source protection zones and recharge area of Jinan spring water, is situated in the southern mountain of Jinan springs city with capital of east China's shandong province. With the development of tourism and agriculture, it has suffered from overloading inputs of increasing population. Some researchers have ever been focus on nitrogen and phosphorus change. However, up to now, no data are available for the pollution status of OCPs. Therefore, investigating organochlorine pesticides residues in circumstances of the reservoir has great significance, because the water quality of the reservoir is closely related to the safety of springs water and drinking water.

\section{Materials and methods}

8 water samples in Jinxiouchuan Reservoir were collected in February 2014, 8 during the dry season. There were evenly distributed in the reservoir upstream, midstream, downstream, inlet and outlet. Because every point had higher detection rate of organochlorine pesticides in the dry season, middle and lower reaches of the South Bank, middle and lower reaches of the North Bank, four 
water samples were added during the wet period in August 2014. Each sample point sampled 8L. 17 kinds of organochlorine pesticides were aimed using Agilent Triple Quadrupole GC-MS (7890A, HP-5). It was operated using electron ionization in the selected ion monitoring (SIM) mode. All data were subject to strict quality assurance and control procedures.

\section{Results and Discussion}

\section{the residues status and season variation of OCPs}

Based on the data, the detection rates of 12 OCPs in the samples are up to $100 \%$, except Heptachlor and Heptachlor epoxide were not detected in all samples, which indicates wide occurrence of these compounds in the Jinxiuchan Reservoir. The total residual concentrations of 17 OCPs ranged from 1.6345 to $4.6479 \mathrm{ng} / \mathrm{L}$ with a mean concentration of $2.7516 \mathrm{ng} / \mathrm{L}$. Several compounds, such as Endrin, Endosulfan II, Dieldrin, DDT were detected in high concentrations in water samples, which suggests the major OCPs. However, the concentrations of HCHs were lower than that of the DDTs and other OCPs. Comparing the detected values of $\Sigma 170 C P s, \Sigma D D T s$, $\Sigma \mathrm{HCHs}$ in the Jinxiuchuan Reservoir to that in other water bodies ${ }^{[3,4]}$, it is found that concentration values were much lower than those of the other waters bodies. Moreover, the present observed concentrations of DDT, Heptachlor epoxide and $\gamma-\mathrm{HCH}$ (Lindane) in Jinxiuchuan Reservoir surface water were much lower than the maximum allowable limits of drinking water sources standards of China (GB3838-2002) which are in $\mu \mathrm{g} / \mathrm{L}$ level ${ }^{[5]}$ (see Table 4) and the threshold value of the US EPA (The amend edition of water quality benchmark, CMC of DDT is $1.1 \mathrm{mg} / \mathrm{L}$ ) ${ }^{[6]}$. This indicated that the water quality of surface water environment in Jinxiuchuan Reservoir is good and very safe for environment by now. Nevertheless, for the safety of drinking water and the health of the people, the monitoring investigation should be strengthened in order to prevent the potential pollution inputs.

Table 117 residues of organochlorine pesticides in each sites sample during dry season (ng/L)

\begin{tabular}{lcccccccc}
\hline OCPs & $\mathrm{S} 1$ & $\mathrm{~S} 2$ & $\mathrm{~S} 3$ & $\mathrm{~S} 4$ & $\mathrm{~S} 5$ & $\mathrm{~S} 6$ & $\mathrm{~S} 7$ & $\mathrm{~S} 8$ \\
\hline$\alpha$-HCH & 0.0151 & 0.0366 & 0.0522 & 0.0623 & 0.0549 & 0.0152 & 0.0304 & 0.0862 \\
$\beta-\mathrm{HCH}$ & 0.012 & 0.0135 & 0.0399 & 0.0085 & 0.0496 & $\mathrm{ND}$ & 0.0109 & 0.0244 \\
$\gamma$-HCH & 0.0289 & 0.0324 & 0.0729 & 0.0868 & 0.1195 & 0.0268 & 0.0151 & 0.0585 \\
$\delta$-HCH & 0.0097 & 0.0526 & 0.01 & 0.0271 & 0.0397 & 0.0186 & 0.0304 & 0.0072 \\
DDE & 0.0937 & 0.1423 & 0.1962 & 0.1842 & 0.2137 & 0.0552 & 0.1107 & 0.3538 \\
DDD & 0.0506 & 0.019 & 0.0147 & 0.0334 & 0.0374 & 0.0249 & 0.0498 & 0.0426 \\
DDT & 0.2472 & 0.2476 & 0.2966 & 0.1243 & 0.2739 & 0.2009 & 0.1154 & 0.1862 \\
Heptachlor & $\mathrm{ND}$ & $\mathrm{ND}$ & $\mathrm{ND}$ & $\mathrm{ND}$ & $\mathrm{ND}$ & $\mathrm{ND}$ & $\mathrm{ND}$ & $\mathrm{ND}$ \\
Aldrin & 0.1027 & 0.0767 & 0.122 & 0.8981 & 0.1337 & 0.2439 & 0.8814 & 0.1551 \\
Heptachlor epoxide & $\mathrm{ND}$ & $\mathrm{ND}$ & $\mathrm{ND}$ & $\mathrm{ND}$ & $\mathrm{ND}$ & $\mathrm{ND}$ & $\mathrm{ND}$ & $\mathrm{ND}$ \\
EndosulfanI & $\mathrm{ND}$ & 0.0451 & 0.0236 & 0.0268 & 0.0513 & 0.0218 & 0.075 & 0.0518 \\
Dieldrin & 0.2382 & 0.3176 & 0.4497 & 0.694 & 0.1079 & 0.2141 & 0.3005 & 0.5699 \\
Endrin & 0.4065 & 0.8483 & 0.7247 & 0.4497 & 0.4866 & 0.8734 & 0.0831 & 2.5384 \\
Endosulfan II & 0.3404 & 0.2722 & 0.27 & 0.2305 & 0.2983 & 0.2044 & 0.3117 & 0.3354 \\
Endrinaldehyde & 0.0588 & 0.0776 & 0.0634 & 0.1682 & 0.0781 & 0.1748 & 0.1731 & 0.0646 \\
Endosulfansulfate & $\mathrm{ND}$ & 0.0686 & $\mathrm{ND}$ & $\mathrm{ND}$ & 0.0516 & $\mathrm{ND}$ & 0.332 & 0.0601 \\
Methoxychloro & 0.0309 & 0.1646 & 0.0487 & 0.0586 & 0.2969 & 0.2952 & 0.6963 & 0.1136 \\
$\sum$ 17OCPs & 1.6345 & 2.4148 & 2.3847 & 3.0526 & 2.2932 & 2.3692 & 3.216 & 4.6479 \\
\hline & & & & & & & & 0.06
\end{tabular}

Note: $\mathrm{S}_{\mathrm{i}}$ stands for Sampling points. "ND" means not detected 
The concentrations distribution of seasonal variation of $\Sigma$ OCPs, $\Sigma$ DDTs, $\Sigma H C H s$ and $\Sigma$ other OCPs in surface water is shown in Fig.1. The concentrations of 17 EOCPs were different with the two seasons. The 17 OOCPs exhibited higher concentrations during the dry season than wet season. This may be due to low temperature after last year's winter. Organochlorine pesticides were not conducive to degradation and volatile, so it was greatly present in the water. However, the degradation of OCPs in water can be accelerated with the higher summer temperature of wet season. Another reason is that water flow rate is larger in wet seasons than in dry season, therefore, OCPs in the water is not suitable to deposit and enrich. Comparing 8 sampling points for the spatial distribution, the content of 17 LOCPs in S1 is the smallest both the two seasons. The S1 is the inlet of the Jinxiuchuang reservoir. According to geographical location, Jinxiuchuan Reservoir has no other surface runoff, and is located in the southern mountains, where the air circulation is good and the atmospheric deposition of $\Sigma$ OCPs is smaller. However, the content of 17 ¿OCPs has increased in other 7 sampling point after entering the water. A small increase of $17 \Sigma$ OCPs in S2-S8 may be due to the scour to surrounding farmland increased after the rain and organochlorine pesticide residues in the soil was washed into the reservoir. The content of $17 \sum$ OCPs in S8 was $4.6479 \mathrm{ng} / \mathrm{L}$, which is highest in all sampling points. This due to this point is the outlet of reservoir, which crossed a woods and sediment may bring organochlorine pesticides in soil into downstream water bodies. For the content of $\Sigma$ HCHs and $\Sigma$ DDTs, S3 and S7 have much higher than other sampling point in wet season. However, the content of $\Sigma$ HCHs and $\Sigma$ DDTs is similar in dry season.
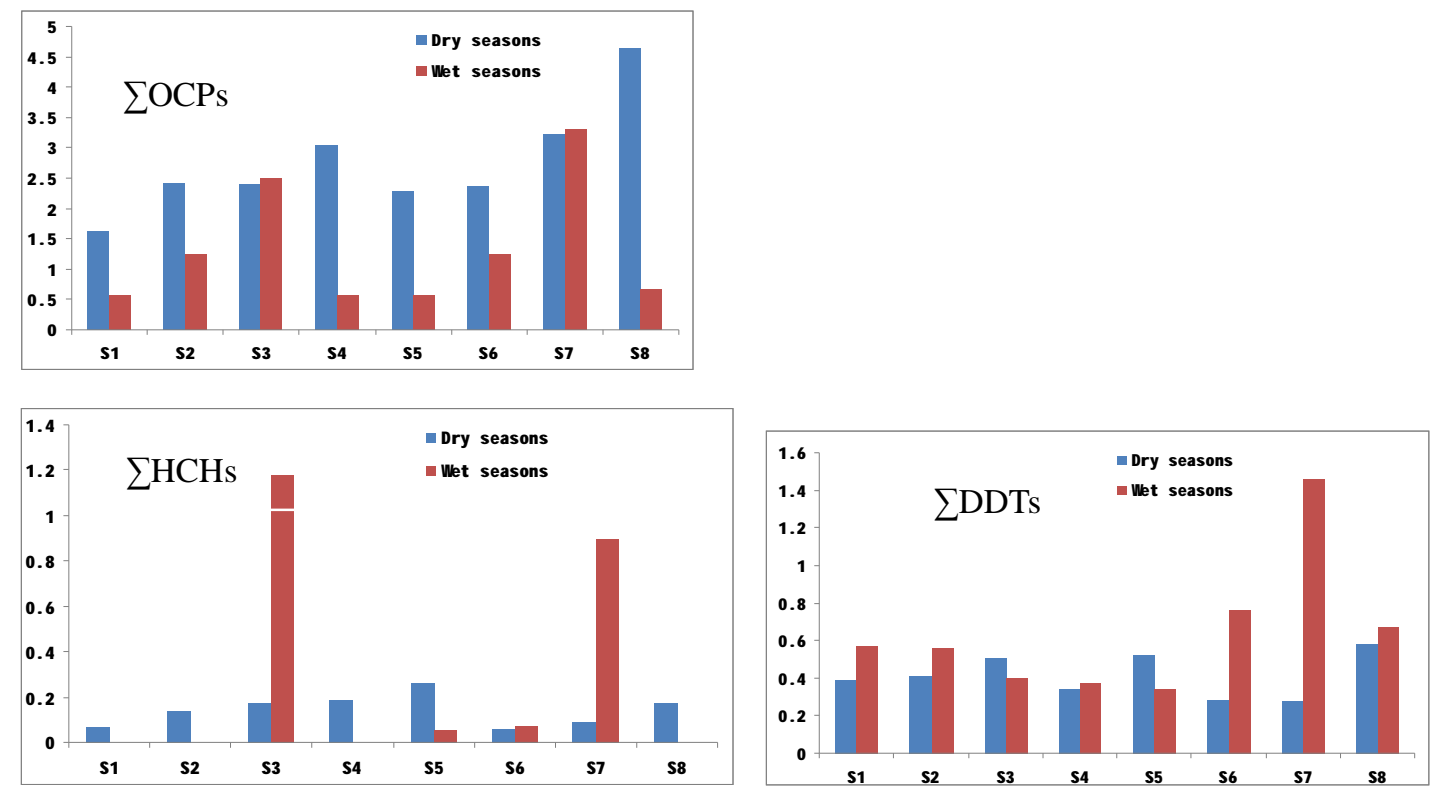

Figure 1 The temporal distribution of $\Sigma$ OCPs, $\Sigma H C H s$ and $\Sigma$ DDTs in surface water Jinxiuchuan Reservoir

\section{Compositions analyses}

The ratio of (DDE+DDD)/DDT can be generally used as indicator to determine whether new DDTs is put into the environment. ${ }^{[7]}$ When the ratio is less than 0.5 , it suggests recent DDT input occurrence; otherwise, it indicates that accumulated DDTs have undergone long-term degradation in the environment. The ratios of water samples are between $0 \sim 2.5$ during the dry season and the wet season (see Fig.2). Besides, the ratio values is greater than 0.5 in $87.5 \%$ samples in the dry season and in $37.5 \%$ samples in wet season, which denoted that the contamination by technical DDT occurred in the past in most of the sampling sites. However, in the wet season, about $62.5 \%$ 
sampling sites had the ratio lower than 0.5 , which revealed new application of DDT existed in the reservoir. Difference between the wet and dry seasons may be derived from a small amount of atmospheric rainfall in the rain season.
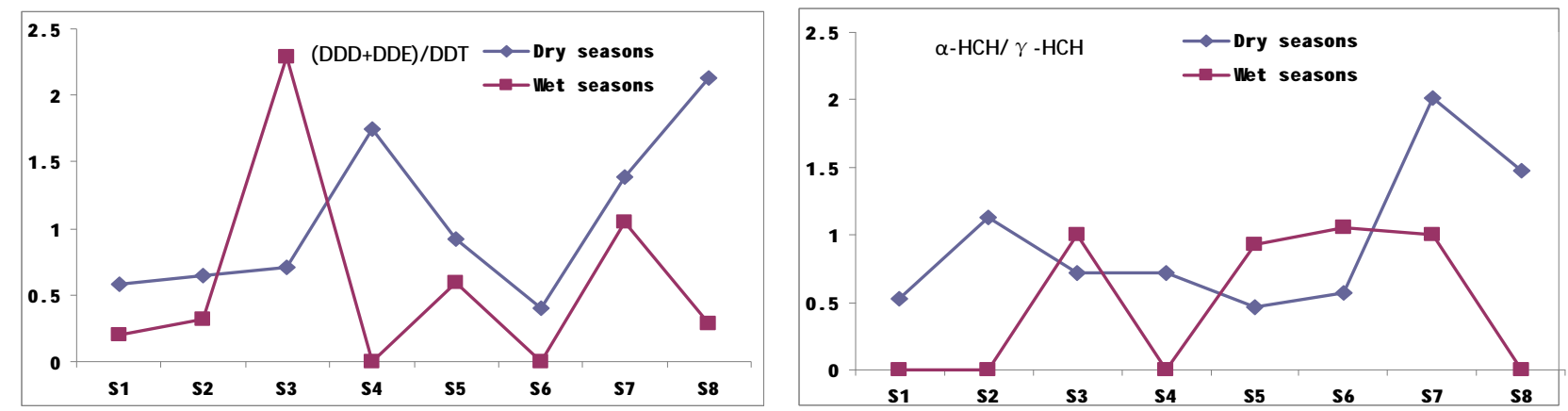

Figure 2 The temporal distribution of ratio of (DDD + DDE) / DDT and $\alpha-\mathrm{HCH} / \gamma-\mathrm{HCH}$ in surface water Jinxiuchuan River Reservoir

The isomer ratio of $\alpha-\mathrm{HCH} / \gamma-\mathrm{HCH}$ was widely used to determine whether $\mathrm{HCH}$ was from technical $\mathrm{HCH}$ or lindane. The ratio of $\alpha-\mathrm{HCH} / \gamma-\mathrm{HCH}$ is ranging from 3 to 7 for technical $\mathrm{HCH}$ and close to zero for lindane ${ }^{[7]}$. As can be seen from Figure 3 , the $\alpha-\mathrm{HCH} / \gamma-\mathrm{HCH}$ ratio in this study ranges from 0.46 to 2.01 in dry season and 0.93 to 1.05 in wet season. This implied that $\mathrm{HCH}$ residues were derived not only from historical technical $\mathrm{HCH}$ use but also from additional use of lindane in this area. . This result is consistent with $\mathrm{HCH}$ sources on soils from suburbs in Jinan.

\section{Conclusion}

Low concentrations of OCPs in the surface water of Jinxiuchuan River Reservoir were found. The residual concentrations of 17 OCPs ranged from 0.1794 to $4.6479 \mathrm{ng} / \mathrm{L}$. The concentration levels of the detected pesticides were far below the target values of China (GB3838-2002) and the threshold value of the US EPA. Moreover, compositions analyses of DDTs and HCHs showed that the presence of detected pesticides was attributed to the intense agricultural activity surrounding the Reservoir. The effects of multi-contamination from pesticide exposure on humans via drinking water are uncertain, and additional work is necessary to reduce this uncertainty.

\section{Acknowledgements:}

This work was financially supported by the University Institutes Innovation Program of Jinan Science and Technology Bureau (No.201102046) and Research Project of Shandong province science and technology development (No. 2014GSF117002).

\section{References:}

[1] L. S. Wang, The Chemistry of Organic Contamination. Beijing: Science Press, 1991.

[2] R. Yang, A. Lv, J. Shi, G. Jiang, The levels and distribution of organochlorine pesticides (OCPs) in sediments from the Haihe River, China, Chemosphere 2005,61,347-354.

[3] G. Dai, X. Liu, G. liang, W. Gong, L. Tao, D. Cheng, Evaluating the sediment-water exchange of hexachlorocyclohexanes (HCHs) in a major lake in North China, Environ. Sci.: Processes Impacts, 2013, 15, 423-432.

[4] S. Eqani, R. Malik, A. Cincinelli, G. Zhang, et. al Uptake of organochlorine pesticides (OCPs) and polychlorinated biphenyls (PCBs) by river water fish: The case of River Chenab, Sci. Total 
Environ., 2013, 450-451, 83-91.

[5] State Environmental Protection Administration of China, GB3838-2002, Environmental quality standard for surface water.

[6] U. S. EPA. National Technical Information Service Accession Number PB85-227049. U. S. Environmental Protection Agency, Washington, DC, 1985.

[7] C. Wu, A. Zhang, W. Liu, Risks from sediments contaminated with organochlorine pesticides, in Hangzhou, China, Chemosphere 2013, 90, 2341-2346. 